\title{
Stability Substance Identifier Terminology
}

National Cancer Institute

\section{Source}

National Cancer Institute. Stability Substance Identifier Terminology. NCI Thesaurus. Code $C 96075$.

Terminology developed to support Substance Identifiers within the Stability Data Standards. 